The Social Sciences 5 (6): 467-470, 2010

ISSN: $1818-5800$

(C) Medwell Journals, 2010

\title{
Gender, Marital Status and Religious Affiliation as Factors of Assertiveness among Nigerian Education Majors
}

\author{
${ }^{1}$ A. A. Arigbabu, ${ }^{2}$ Owolabi-Grabriel and ${ }^{3}$ Oladipo Samuel Ekundayo \\ ${ }^{1}$ College of Science and Information Technology, Tai Solarin University of Education, \\ Ijagun, Ijebu Ode, Ogun State, Nigeria \\ ${ }^{2}$ Department of Education Psychology, Tai Solarin College of Education, \\ Omu, Ijebu, Ogun State, Nigeria \\ ${ }^{3}$ College of Applied Education and Vocational Technology, \\ Tai Solarin University of Education, P.M.B. 2118, Ijagun, Ogun State, Nigeria
}

\begin{abstract}
Using an ex-post facto survey research design, the present study examined the influence of gender, marital status and religious affiliation on assertiveness of education majors. For the purpose of the study, 367 education majors were randomly selected from two institutions. This was made up of $96(26.2 \%)$ males and 271 (73.8\%) females; $165(45 \%)$ married, 191 (52\%) singles and 11 (3\%) widowed. Participants' ages ranged between 17-53 years. Validated scales were used to collect data which was analyzed using univariate analysis of variance. The result showed that none of gender, martial status or religious affiliation had statistically significant influence on the assertiveness level of education majors.
\end{abstract}

Key words: Education major, assertiveness, pre-service teachers, N.C.E. students, university raduates

\section{INTRODUCTION}

Assertiveness could simply be described as the ability to express oneself as well as one's rights without violating the rights of others. In other words, it is the ability of an individual to express his thoughts and feelings in a way that clearly states his needs and keeps the lines of communication open with the others. It should be mentioned, however that many people feel that attending to their legitimate needs and asserting their rights translates to being selfish. This is not so because selfishness means being concerned about one's rights only with little or no regard for others. Though being assertive has a number of benefits, such as the feeling of self confidence and gaining the respect of friends and peers. It can also increase the chances for honest relationship and possibly increase the chances for getting what one really wants from life.

Lack of assertiveness has been identified by researchers to affect students both nationally and internationally and a lot of arguments both within and outside the academic environment have always emanated when both genders are compared with respect to assertiveness unfortunately, there is limited empirical literature in this area (Poyrazli et al., 2001) incidentally, same also goes for Nigeria.

The general assumption is that men are more assertive than women and where the latter become assertive, they experience unique problems (Adejumo, 1981). The fact is that sex roles are somewhat rigid in Africa and gender differences are emphasized (Onyezuigbo, 2003). In Nigeria for instance, men are expected to be more assertive (even aggressive), ambitious and strong whereas women are expected to be submissive, passive and gentle (Onyezuigbo, 2003). Frankly speaking, the double standard thus, created as shown in the above borders on sexism and thus, imposes a limit on the extent to which women can assert or express themselves. For example in the Yoruba culture (a sub-set in the South-West of Nigeria), whatever a woman has as her possession is believed to automatically belong to her husband. This is in concert with the proverbial saying that the owner of the slave automatically owns the slave's properties. In other words, the woman is actually seen as the husband's property hence, she is not to assert herself, in addition to this, the culture also permits the man to have many wives.

In the light of the above, one may be tempted to say that there is no hope for the womenfolk, however a wave of change seem to have crept in particularly in the last two decades in this part of Nigeria. Also, the Beijing conference of 1995 has been an eye opener for many women worldwide consequently, women particularly those in urban cities are more aware, now than ever before of the need to claim their rights and assert themselves.

Corresponding Author: A. A. Arigbabu, College of Science and Information Technology, Tai Solarin University of Education, Ijagun, Ijebu Ode, Ogun State, Nigeria 
Review of related literature revealed that a difference exists between the level of assertiveness among males and females. For instance, Hersen et al. (1973), Ory and Helfrich (1976), Adejumo (1981) and Eskin (2003) all reported men to be more assertive than women. This was however, contradicted by some other studies. For instance, Chandler et al. (1978) found that women were significantly more assertive than men in some specific situations. For instance, women (college students) were more willing to be socially confrontative more willing to present themselves in person in competitive situations such as job interviews and more open and frank about their feelings.

Despite the above findings, it is also interesting to note that Maccoby and Jacklin (1974) and Applebaum (1976) have found that there is no consistent tendency for one gender to be more assertive than the other. In a more recent international study on assertiveness, Poyrazli et al. (2001) found that there is high correlation between assertiveness and academic performance as well as adjustment problems. They reported that students with higher level of assertiveness reported being more selfefficacious academically, this thus suggests that students who are more assertive probably initiate more academic interactions or ask for academic help and therefore have higher academic self-efficacy. This finding is consistent with those of Bandura (1986), Maddux and Meier (1995) and Chen (1992).

Part et al. (1992) found that one of the cultural differences international students are particularly concerned about is assertiveness. This is consistent with the findings from two previous studies which indicated that both male and female Finnish and Japanese college students and also female Korean college students are less assertive than their American counterparts (Thompson et al., 1990; Thompson and Klopf, 1995). The implication of this that because of these differences, international students may become confused about how to interpret their environment and respond in a relatively more assertive culture. Depending on their cultural backgrounds, some of the students may not be assertive enough to search or ask for help on their own. As a result, they may be handicapped in their relationship with other students and lecturers who are considered as important in their academic pursuit which may invariably affect their academic performance negatively.

The review of literature for the purpose of this study showed that considerable research has been done in the area of assertiveness but most of these studies have tended to look at just one variable (which most likely must have had considerable influence on the findings of such research works). For example the research of researchers like Gay et al. (1975), Hollandsworth and Wall (1977), Kern
(1996), Kern et al. (1985) and Kimble et al. (1984), all focused primarily on gender and assertiveness. Others focused solely on women (Wolfe and Fodor, 1977). Few studies have addressed a combination of such factors as age, gender and education e.g., Comas-Diaz and Duncan (1985), Melgoza et al. (1983), Roll et al. (1996), Soto and Shaver (1982) and Yoshioka (1995). Therefore, additional research in this area is of necessity so as to find out other possible variables that may influence assertiveness in people hence, the conduct of this present study which is set to find out the influence of gender, marital status and religious affiliation on assertiveness among undergraduates in Nigeria.

Based on the foregoing, the following hypothesis was stated and tested. Gender, marital status and religious affiliation will significantly influence assertiveness among education majors in Nigeria.

\section{MATERIALS AND METHODS}

Instrument: The Rathus Assertiveness Schedule (RAS) was used for data collection. The instrument of data collection was divided into two sections. The first section tapped for the participants' demographic data while the second section was the Rathus Assertiveness Schedule (RAS) which has a test-retest reliability $(0.77)$ and high validity (0.93). For the present study, the coefficient alpha of RAS is 0.62 .

Research instrument was administered to students on an agreed date. This was possible because the students had already been approached and intimated with the research aims and objectives and those who indicated interest in participating in the study were informed of the date and venue of the test. On the agreed date, test instrument was administered to participants and retrieved on the same day.

Participants: The study is an ex-post facto field survey. Participants were 367 pre-service science teachers, randomly selected from two institutions of higher education in South-West Nigeria. They were two of two categories: $\mathrm{NCE}(\mathrm{N}=127)$ and university undergraduates $(\mathrm{N}=240)$.

By NCE is meant pre service teachers that are undergoing the 3 years teacher preparation training under the Nigeria certificate in education program. The university undergraduates on the other hand are those who are undergoing the 4 years teacher preparation training in the university to become professional teachers. The sample is made of $96(26.2 \%)$ males and $271(73.8 \%)$ females. About 165 (45\%) of the participants were married; $191(52 \%)$ were single while $11(3 \%)$ were widowed. Participants' ages ranged between 17-53 years. 


\section{RESULTS AND DISCUSSION}

The stated hypothesis was analyzed using univariate analysis of variance. Result shows that gender was not a significant predictor $(\mathrm{df}=2, \mathrm{~ms}=0.77, \mathrm{f}=3.17, \mathrm{p}>0.05)$. In other words, there was no significant difference in the assertiveness level of male and female students. Analysis also showed that marital status was not a significant predictor of assertiveness of students $(\mathrm{df}=2, \mathrm{~ms}=0.66$, $\mathrm{f}=2.71, \mathrm{p}>0.05$ ). In other words, marital status does not have significant influence on assertiveness. The implication of this is that an individual's level of assertiveness is not significantly predicted by whether he is married, divorced, separated or single.

In addition to the results, analysis with respect to religious affiliation showed no statistically significant difference. In essence religious affiliation was not found to be a significant predictor of assertiveness among the sample set $(\mathrm{df}=2, \mathrm{~ms}=0.07, \mathrm{f}=0.27, \mathrm{p}>0.05)$.

The finding that gender is not a significant predictor of assertiveness among undergraduates contradicts previous findings of some $\mathrm{s}$ researchers such as Hersen et al. (1973), Ory and Helfrich (1976), Adejumo (1981) and Eskin (2003) who all reported that men are more assertive than women. In the same vein, this finding is also at variance with reports of researchers like Chandler et al. (1978) who found that women were significantly more assertive than men in some specific situations. Although, one would have expected that gender would be a significant predictor of assertiveness among the samples used in the study, this is basically because of the culture that operates in the setting where the research was conducted. However, the reverse is the case. This present finding may possibly have been the influence of exposure to higher education which has brought about a change in their orientation as well as their cultural beliefs about gender bias.

With no disparity in assertiveness level of male and female students, it is expected that there will be uniform and or healthy competition among the students which can facilitate academic progress and development on campus. The lack of a statistically significant prediction of assertiveness by gender could be an indication that there is a possibility of erasure of the feeling of intimidation expressed by some females as well as their feeling of being opposed, rejected or shouted down.

Marital status of participants was also not a significantly predictor of assertiveness among the students. A quick literature search reveals that not much has been done with respect to marital status as a variable that may predict assertiveness among students, particularly in Nigeria.
Although, one would think that marital status should be a significant predictor of assertiveness; the reason being that culturally, the unmarried are mostly considered as being free without restrictions per sec. For instance while the unmarried may take prompt and unilateral decisions on issues, the married may not be able to do same as they are more or less supposed to discuss with their spouses or put their spouses into consideration before taking a decision. However, the finding of this study has shown that there is no significance difference in the assertiveness level of students based on their marital status.

Finally, the third variable of interest in the study which was also examined was religious affiliation and the result of analysis showed that religious affiliation is a not a significant predictor of assertiveness among education majors. This thus, implies that an individual's religious affiliation does not have significant influence on his/her assertiveness in other words, other variables apart from religious affiliation may more significantly influence assertiveness among students.

The assumption must have been that individuals do not link their religious practices and believes with their level of assertiveness. In essence, participants might have viewed religion as a purely spiritual matter that has nothing to do with their assertiveness (which is a psychological variable).

\section{CONCLUSION}

This study examined the variables: gender, marital status and religious affiliation as factors of assertiveness level of tertiary institution students. The hypothesis stated and tested showed that none of these variables is a significant predictor of assertiveness among education majors. The conclusion, therefore is that other variables apart from gender, marital status and religious affiliation might account for difference in the assertiveness level of education majors hence, the need to conduct more research that will focus on other variables.

\section{REFERENCES}

Adejumo, D., 1981. Sex differences in assertiveness among university students in Nigeria. J. Soc. Psychol., 113: 139-140.

Applebaum, A.S., 1976. Rathus assertiveness schedule: Sex differences and correlation with social desirability. Behav. Ther., 7: 699-700.

Bandura, A., 1986. Social FOundation of Thought and Action: A Social Cognition Theory. Englewood Cliffs, NJ: Prentice Hall. 
Chandler, T.A., B. Cook and D.A. Dugovics, 1978. Sex differences in Self-reported assertiveness. Psychol. Rep., 9: 33-41.

Chen, G.M., 1992. Communication adaptability and interaction involvement as predictors of Crosscultural adjustment. Commun. Res. Rep., 9: 33-41.

Comas-Diaz, L. and J.W. Duncan, 1985. The cultural context: A factor in assertiveness training with mainland Puerto Rican women. Psychol. Women Quarterly, 9: 463-476.

Eskin, M., 2003. Self-assertiveness in Swedish and Turkish Adolescents: A Cross-cultural comparison. Scandinavian J. Psychol., 44: 7-12.

Gay, M.L., J.G. Hollandsworth and J.P. Galassi, 1975. An assertiveness inventory for adults. J. Counseling Psychol., 22: 340-344.

Hersen, M., R.M. Eisler and P.M. Miller, 1973. Development of assertive responses: clinical measurement and research consideration. Behav. Res. Ther., 11: 505-521.

Hollandsworth, J.G. and K.E. Wall, 1977. Sex differences in assertive behavior: An empirical investigation. $\mathrm{J}$. Counseling Psychol., 24: 217-222.

Kern, J. M., T.A. Cavell and B. Beck, 1985. Predicting differential reactions to males versus females assertions, empathic-assertions, and non assertions. Behav. Ther., 16: 63-75.

Kern, J.M., 1996. Objective detection of faking on roleplay tests of assertion: Gender differences. Psychol. Rep., 78: 355-361.

Kimble, C.E., N.B. Marsh and A.C. Kiska, 1984. Sex, age and cultural differences in self-reported assertiveness. Psychol. Rep., 55: 419-422.

Maccoby, E.E. and C.N. Jacklin, 1974. The psychology of sex differences. Standford, C.A: Standford University Press.

Maddux, J.E. and L.J. Meier, 1995. Self-efficacy and Depression. In: Self-Efficacy, Adaptation and Adjustment: Theory, Research and Application, Maddux, J.E. (Ed.). Plenum Press, New York, pp: $143-172$.
Melgoza, B., S. Roll and R.C. Baker, 1983. Conformity and cooperation in chicanos: The case of the missing susceptibility to influence. J. Commu. Psychol., 11: 323-333.

Onyezuigbo, E.U., 2003. Effects of gender, age and education on assertiveness in a Nigerian sample. Psychol. Women Quarterly, 27: 12-16.

Ory, J.C. and L.M. Helfrich, 1976. A study of individual characteristics and career aspiration. In: Chandler, T.A., B. Cook and D.A. Dugovis (Eds.). 1978. Sex Differences in Self-Reported Assertiveness. Psychological Reports, 43, pp: 395-402.

Part, G., L. Bradley and R. Bingi, 1992. Concerns and feelings of international students. J. Coll. Student Dev., 33: 20-25.

Poyrazli, S., C. Arbona, R. Bullington and S. Pisecco, 2001. Adjustment problems of Turkish international student studying in the United States. Coll. Student J., 35: 52-62.

Roll, S., G. McClelland and T. Abel, 1996. Differences in susceptibility to influence in Mexican American and Anglo females. Hispanic J. Behav. Sci., 18: 13-20.

Soto, E. and P. Shaver, 1982. Sex-role traditionalism, assertiveness, and symptoms of Puerto Rican women living in the United States. Hispanic J. Behav. Sci., 4: $1-19$.

Thompson, C.A. and D.W. Klopf, 1995. Social style among North American, Finnish, Japanese, and Korean university students. Psychol. Rep., 77: 60-62.

Thompson, C.A., S. Ishii and D. Klopf, 1990. Japanese and Americans compared on assertiveness/ responsiveness. Psychol. Rep., 66: 829-830.

Wolfe, J.L. and I.G. Fodor, 1977. Modifying assertive behavior in women: A comparison of three approaches. Behav. Ther., 8: 567-574.

Yoshioka, M., 1995. Measuring the assertive behavior of low-income, minority women: Culturally appropriate versus mainstream criteria. Dissertation Abstr. Int., 56: 1129-1129. 